$\mathrm{BFJ}$

123,3

Received 1 June 2020 Revised 22 July 2020 21 September 2020

Accepted 1 November 2020

\section{PDO labels and food preferences: results from a sensory analysis}

\author{
Elisabetta Savelli and Laura Bravi
}

Department of Economics, Society, Politics, Università degli studi di Urbino Carlo Bo, Urbino, Italy

Barbara Francioni

Department of Communication Sciences, Humanities and International Studies, Cultures, Languages, Literatures, Arts, Media, University of Urbino Carlo Bo, Urbino, Italy, and

Federica Murmura and Tonino Pencarelli

Department of Economics, Society, Politics, Università degli studi di Urbino Carlo Bo, Urbino, Italy

\begin{abstract}
Purpose - The paper aims at investigating whether and how the product designation of origin (PDO) label influences consumers' acceptance, attributes' perception and purchase intention of PDO foods.

Design/methodology/approach - The study employs an experimental lab study based on the affective test of acceptance methodology with a nine-point hedonic scale. Three PDO foods are compared with similar nonPDO samples concerning cheese, cured ham and olive oil categories.

Findings - The presence of PDO labels enhances the consumers' acceptance as well as their perception of sensory attributes. A critical role of the brand name as an enhancer of consumer acceptance also emerges, highlighting the relationship between brand-name and PDO label.

Research limitations/implications - The main limitation is related to the lab study methodology, which employs a small number of participants and occurs far from a "normal" situation of consumption. The acceptance test, moreover, does not provide explanations about motives underlying the differences in consumers' perception and preferences.

Practical implications - Practical implications are suggested for food companies concerning the management of both PDO labels and brand strategies and the product's properties that could improve the sensory perception of consumers and their overall product's acceptance.

Originality/value - The study contributes to the debate on consumer behaviour towards PDO foods by adding evidence about the positive influence of such a certification on individual preferences on the basis of a sensory methodology that has been little employed for studying the domain of product certifications.
\end{abstract}

Keywords Typical food, PDO label, Sensory analysis, Acceptance test, Italian food

Paper type Research paper

\section{Introduction}

Consumer interest towards food quality and safety is increasing with an improving awareness of food-borne illnesses due to a number of food scandals and incidents that are continuously happening without any sign of decrease (Dora et al., 2013; Rafeeque and Sekharan, 2018). According to Vermeir and Verbeke (2006), the public concern in safety, healthiness, sustainability and social issues on production practices haveincreased at every level of the food chain. Therefore, it is essential for companies to improve quality assurance and transparency, by using advanced

(C) Elisabetta Savelli, Laura Bravi, Barbara Francioni, Federica Murmura and Tonino Pencarelli. Published by Emerald Publishing Limited. This article is published under the Creative Commons Attribution (CC BY 4.0) licence. Anyone may reproduce, distribute, translate and create derivative works of this article (for both commercial and non-commercial purposes), subject to full attribution to the original publication and authors. The full terms of this licence may be seen at http://creativecommons.org/licences/ by/4.0/legalcode 
traceability systems to prove both the origin and the final quality of foods (Alfian et al.,2017), such as those defined by the international standard ISO 22000, 2005, which specifies requirements for a food safety management system (FSMS) where an organization in the food chain needs to demonstrate its ability to control food safety hazards in order to ensure that food is safe at the time of human consumption (ISO 22000, 2005; Rafeeque and Sekharan, 2018).

Besides system certifications, additional tools made available to the consumer for the analysis of food safety are the regulated agri-food product certifications, aimed at promoting the products' uniqueness linked to the geographical origin as well as to the traditional knowhow. The main European geographical indication (GI) schemes include protected geographical indications (PGI), protected designation of origins (PDO) and traditional speciality guaranteed (TSG) labels. The European system of GI mainly permits to (1) enhance the productive system and the economy of the territory; (2) protect the environment because the indissoluble link with the territory of origin requires the protection of ecosystems and biodiversity; (3) support the social cohesion of the whole community. Moreover, owing to the community certification, consumers are given greater guarantees with a higher level of traceability and food safety than other products (https://www.politicheagricole.it).

Literature says that consumer awareness and comprehension of GI label information are crucial for determining, maintaining and communicating their value (Kos Skubic et al., 2019). These labels may help ensure that consumers can correctly judge a product at the same time as enabling the producer to adapt production to meet consumer demands and expectations, promoting social or economic objectives (Erraach et al., 2014).

Despite the time lapse since their inception, the debate continues concerning awareness of GI labels and their effect on consumers' attitudes, preferences and quality perception (Erraach et al., 2014). Moreover, Grunert and Aachmann (2016) stressed the necessity of a solid base of research on the way in which such labels do or can affect consumer behaviour in order to implement an evidence-based policy in this area. Notably, they suggest going deep into the role of GI labels in decision-making processes, using a methodology that is different from the classic surveys based on self-reported ratings. The same has been recently underlined by Marcoz et al. (2016) and Kos Skubic et al. (2018).

Coming from these evidences, the purpose of the present study is to cover the above research gaps, by assessing whether and how the GI certification, especially the PDO label, influences consumers' preferences and acceptance, their attributes' perception and purchase intention. Findings from prior research on the role of PDO labels, indeed, are particularly controversial, with some authors considering it as a critical antecedent of consumers' behaviour (e.g.: Bryla, 2017, 2019; Kos Skubic et al., 2018; Kos Skubic et al., 2019; Menapace et al., 2011) and others finding it as a factor of minor influence (Fotopoulos and Krystallis, 2001; Marcoz et al., 2016).

In order to achieve our objective, an experimental lab study has been developed, based on the affective test of acceptance methodology. As a typology of sensory analysis, acceptance tests have been increasingly used in marketing research (Aumatell, 2011), also including the food setting (Lyon et al., 2012), as they allow to investigate the sensory perception of a product by the consumer, using the human senses as a critical point to the evaluation (Silva and Ferreira, 2017). Notwithstanding their usefulness, to the best of the authors' knowledge, the sensory analysis has been little employed for studying the domain of product certifications despite its possibility of being great in value for comparing product with different labels, including PDO certifications, and displaying similarities and differences among them in consumers' perception (Rodrigues et al., 2018; Mora et al., 2020).

Two main research questions operationalize the above-mentioned purpose:

$R Q 1$. Are consumers' acceptance of food and perception of food sensory attributes influenced by the presence of PDO labels? 
BFJ

123,3

$R Q 2$. How do PDO labels exert their influence on the overall preference and purchase intention of food by consumers?

The analysis has been focused on three typical Italian foods, namely cheese, cured ham and olive oil with a PDO label, that have also been compared with three conventional products of the same category but with a commercial brand.

The rest of the paper is structured as follows: Section 2 describes the literature background; Section 3 explains the methodology; Section 4 presents the results while Section 5 discusses them and draws some implications. Finally, Section 6 depicts the main conclusions of the study, as well as its limitations and future research directions.

\section{Theoretical background}

\subsection{Typical and certified foods}

Over the last decade there were consumers' growing interests in both typical products and quality, creating a demand for agricultural products and foodstuffs with specific, identifiable characteristics, particularly those that are linked to their geographical origin and their production method (Hajdukiewicz, 2014; Dias and Mendes, 2018).

A typical product has been defined by Nosi and Zanni (2004, pp. 781-782) as a product "characterized by distinct historical and cultural features and by physical attributes that are deep-rooted to the territory of origin encompassing therefore much more than bare texture". According to Savelli et al. (2019a) a typical product is the combination of two main characteristics, i.e. the place of origin and the adoption of traditional production techniques. PDO products are like typical products, but they differentiate themselves because of a more compelling regulatory system that protects their origin, ensuring a complete conformity of the product with measures and norms. Notably, the European geographical indication schemes defend specific know-how, authenticity and agro-environmental conditions; and protect the name of a product that comes from a specific region and follows a particular traditional production process.

More details on the meaning of PDO labels emerge from the European regulation introduced in 1992 by the European Union, which created three typologies of protected geographical status for both food and wine, such as PDO, PGI and TSG (Bonetti et al., 2019). PDO and PGI mainly have the role to protect the name of a product that comes from a specific region and follows a traditional production process. In particular, for PDOs, the raw ingredients have to come from the region of origin where all steps of production need to take place. As for PGIs, at least one of the stages of production, processing or preparation has to take place in the area of origin. Finally, TSG labels are aimed at underlining the traditional aspects of a product, such as the way it is made or its composition, without being linked to a specific geographical area (Grunert and Aachmann, 2016).

Italy is the European country with the highest number of GI-labelled agri-food products, with 299 PDO, PGI and TSG products and 524 wines with a denomination of controlled and guaranteed origin (DCGO), Denomination of controlled origin (DCO) and typical geographical indication (TGI). This suggests the strong bond that binds the Italian agri-food excellence to its territory of origin (https://www.politicheagricole.it).

Product certification makes sure that a product complies with what is specified and declared by the manufacturer and ensures compliance with requirements such as quality characteristics and the place of origin (Grunert and Aachmann, 2016; Hajdukiewicz, 2014). They are expected to offer food safety guarantees based on their traceability and authentication as well as on the high organoleptic qualities (Trabelsi-Trigui and Giraud, 2012). Notably, one of the main objectives of $\mathrm{PDO}$, on which this study is focusesd, is to provide a competitive alternative for local productive systems specialized in food products. In detail, olive oil, cheese and jam are food products with strong roots in the place of origin. Olive oil is a vegetable, which differentiation is mainly vertical, and it is based on the degree of acidity (i.e. extra virgin, virgin, not virgin, mixes, etc.) that comes 
from olives' picking and the extraction system. So far, differentiation based on the recalled attribute has been more relevant for consumers in traditional consuming countries and less relevant for the so-called new consumers (Cacchiarelli et al., 2016). Most of the literature focuses on studying the authentication of PDO olive oils or the olive cultivars used in their production. Southern European countries are most analysed, particularly Italy and Portugal (Dias and Mendes, 2018).

As for cheese, in the literature panorama, it is the relationship between cheese and milk that raised the research interest; according to the literature review by Dias and Mendes (2018), the study by Mallia et al. (2005) is the only one to analyse the differences between PDO cheeses from different countries, but Italy is the country most studied, especially the "Mozzarella di Bufala Campana" cheese. However, no studies have been found on analysing consumers' perception of food quality of cheese for PDO products.

Finally, about ham, this food product is widely investigated in the Spanish literature panorama (Cilla et al., 2006; Resano et al., 2007), but also Italy has been deeply investigated mostly with reference to the Parma ham. The work of Van Ittersum et al. (2007) analysed consumers' decision-making process by considering some European typical products, including the Parma ham. They found that consumers of regional products are quite sensitive to the PDO labels, having a positive attitude towards them, thanks to the quality warranty dimension and to the local economic support.

\subsection{The role of $P D O$ in food product evaluation by consumers}

The criteria used by consumers when making day-to-day food choices have been widely examined by prior research. Several studies show that consumers make their choices by focusing on different variables that help them to both maximise the advantages and minimise the losses involved in a purchase (Reitano et al., 2016; Savelli et al., 2019b). Prior research (Asioli et al., 2017; Fandos and Flavian, 2006; Garavaglia and Mariani, 2015) also highlights that, in many cases, purchasing decisions are guided by consumers' perceptions regarding both the intrinsic and extrinsic attributes of a product. Intrinsic attributes have an important role in the consumers' product evaluation (De Pelsmaeker et al., 2013). These include specific characteristics to each product that cannot be altered or manipulated without modifying the product itself, such as sensory properties (e.g. texture, appearance, taste, flavours) or product composition (e.g ingredients) (Asioli et al., 2017; Fandos and Flavian, 2006). On the other hand, extrinsic attributes, while being product-related, are not part of it, therefore they can be modified without changing the product itself (Fandos and Flavian, 2006). These include brand name, price, packaging, health/sustainability claims, place of origin and quality labels (Asioli et al., 2017; Lähteenmäki, 2013). Often, intrinsic properties are difficult to evaluate for the consumer, given that perfect information about them, especially those on products' quality and safety, are hardly available in food markets, therefore, consumers' evaluations and purchase decisions need to refer mainly to extrinsic attributes, including brand names and quality labels. In this respect, prior studies (e.g. Fotopoulos and Krystallis, 2001, p. 4) stressed the fact that a PDO label cannot have "a similar value to an old, worldwide known and heavily advertised brand name", but it could provide a competitive advantage similar to that of a brand name, especially to small producers.

As a result, there is a growing interest towards the examination of PDO labels, and several studies have investigated the impact of PDO label on consumers' purchasing behaviours. By considering some European typical products, Van Ittersum et al. (2007) found that consumers of local products are quite sensitive to PDO labels, having a positive attitude towards them, mainly due to their quality warranty dimension. Menapace et al. (2011) compared the simple indication of origin and official certifications of origin for olive oil. They observed that official certifications, and particularly PDO, are considered by consumers to be reliable indicators of product quality. Similarly, Tendero and Bernabéu (2005), by studying the Spanish cheese market, reported that labels reassure consumers about the place of production and thus serve as a food safety 
$\mathrm{BFJ}$

123,3

guarantee. Through quantitative researches and an examination of Spanish products, Fandos and Flavian (2006), and later Espejel et al. (2008) discovered that consumers give the PDO labels a great value during their buying intention, especially because they provide a distinctive and certified element of quality. An additional study of Kos Skubic et al. (2019) shows that quality perception is strongly influenced by the belief that the PDO signals better tasting products. A study of Bryla further confirmed the existence of a positive relationship between quality signs for origins and the purchase intention, willingness to pay and the overall attitudes of consumers towards organic food (Bryla, 2017). Notably, in a more recent study, he also noted that the positive impact of such certifications on purchase intention depends on the degree of regional ethnocentrism of consumers. Hence, individuals with a high preference for products originating from their regions are more likely to be influenced by signs for origins (Bryla, 2019).

Although the majority of researches demonstrate the positive influence of PDO labels on consumers' decision-making process, some studies reveal that this element is not always considered as one of the most important aspects. For instance, Fotopoulos and Krystallis (2001) found that although many consumers view PDO products positively and are willing to pay a premium price for them, for more than a third of the buyers this label is of minor relevance. Marcoz et al. (2016) underlined how the importance of PDO label depends of the geographical distance of consumers from the product's place of origin. Thus, consumers from the same region tend to consider PDO certification as the least important element since they know the product and do not care whether it is certified or not.

The above contradictory results highlight the need for further investigations on this topic, with the aim to better understand the relationship between PDO labels and consumers' responses, especially through the adoption of innovative techniques, as suggested by Grunert and Aachmann (2016), which differ from traditional self-report methods.

\section{Methodology}

A sensory analysis based on the affective test methodology was performed in this study to determine the preference gap of consumers in tasting PDO foods compared to non-PDO ones, with the aim of understanding to what extent the product certification can improve a consumers' acceptance of the product, as well as their perception of sensory attributes (RQ1).

Affective tests are increasingly widespread in marketing research (Aumatell, 2011), especially in the food context (Lyon et al., 2012). The perception of food by consumers, indeed, is closely linked to what they experience of the product in a holistic and unitary way, rather than to a careful evaluation of the individual attributes characterizing the product (Kim $e$ t al., 2015). Therefore, consumers tend to develop an affective rather than rational perceptive process (e.g.: Dijksterhuis and Byrne, 2005; Frandsen et al., 2007), and affective tests are much more valuable than other descriptive and/or discriminatory sensory experiments.

After completing the sensory test, a brief interview was directed to the participants aimed at investigating the impact of the PDO label on their attitudes in terms of global preference and willingness to purchase (RQ2).

\subsection{Test design and procedures}

A digital questionnaire form was developed for the study, which was structured into three sections.

The first two sections were employed during the acceptance test execution for gathering information about consumers' acceptance of the food samples and the perception of their sensory attributes (RQ1). In detail, the first part included one question aimed at assessing participants' acceptance of the food samples, while the second one explored the consumers' perception of foods' sensory properties expressed in terms of appearance, smell, flavour and texture. Food samples are made of 3 PDO labelled food products (cheese, cured ham and olive oil) and 
respectively 3 conventional food products of the same category. Both evaluations were measured through a nine-point hedonic scale $(1=$ dislike extremely, $9=$ like extremely). Peryam and Girardot (1952) originally developed this scale at the Quartermaster Food and Container Institute of the US Armed Forces, with the purpose of measuring the food preferences of soldiers. It was quickly adopted by the food industry as it is more discriminating than shorter scales (Lawless and Heymann, 2010). The third section of the questionnaire included three close-ended questions aimed at investigating the impact of PDO labels on consumers' preference and intention to purchase (RQ2). The willingness to pay (price/kg) was further asked in this section as it has been often considered as an indicator of purchasing intention (Tung et al., 2012; Xu et al., 2017). These questions were asked after completing the acceptance test and having ascertained the overall judgement of acceptability so as not to penalize the less appreciated products. Participants were asked to rate their answers by using different Likert scale response anchors. As concerning the product preference, they used a three-point scale $(1=$ better than, $2=$ similar to, $3=$ worse than $)$ for comparing all samples proposed with similar products they normally used (Compared to the product you normally use, how do you rate the overall quality of this sample.). The purchasing intention was measured by using the following question based on Spears and Singh (2004): If you would need a cheese/cured ham/olive oil, would you be willing to buy the present sample? In this case, a structured 5-point Likert scale was used ranging from 1 (= certainly would not buy) to 5 (= certainly would buy). Finally, the willingness to pay was measured as an equally spaced ordinal categorical variable ranging from 1 to 5 (Kim et al., 2018). The central value of the scale was identified based on the current average market price of each product category. Participants were asked to indicate the maximum price they were willing to pay on the proposed price scales.

The food samples were presented to the panellists in two steps. First (blind tasting), each sample was shown without any communication reference (concerning its brand name and PDO label,) and it was placed in a container coded with a random three-digit number. Second (brand tasting), consumers tasted the samples in a reference information context, knowing their brand name and PDO label. Thus, for each product category, all panel members rated four samples (i.e. the PDO product and its counterpart in a blind and non-blind situation).

Repeating the test in a blind and non-blind situation allows to understand whether the global acceptance, perception and preference of the consumer are influenced mainly by the degree of notoriety of the PDO and non-PDO brands or depend on the fact that consumers differently perceive the intrinsic attributes that are associated with the certified sample and non-certified one.

The samples were shown according to a completely randomized design, and they were homogeneously presented in terms of shape, quantity and temperature in order to limit psychological influences in the sensory evaluations of the panel. Each presentation was accompanied by an evaluation form highlighting instructions for a correct execution of the test (e.g. "examine the samples from left to right").

The test was performed by the Italian Center of Sensory Analysis (CIAS Innovation), a service company that is specialized in sensory analysis and consumer science research, operating in compliance with UNI EN ISO 8589, 2010 regulation with regard to methodologies and preparation environment.

\subsection{Food samples}

Italy was chosen as a country of analysis because it is considered one of the most important countries worldwide with regard to PDO products (ISMEA-Fondazione Qualivita, 2018), which "account for 6.96bn euros (sell in) and over 14bn euros (sell out)" (Bonetti et al., 2019, p. 391).

Six food samples commonly used by Italians, and generally available in large-scale retail channels, were selected, grouped into three categories that are cheese, cured ham and olive oil. For each product category, one typical food with PDO label was compared with a conventional non-PDO competitor. PDO products were selected from the Province of Pesaro 
$\mathrm{BFJ}$ 123,3

1176

and Urbino: an area rich in pastures, cattle ranches and olive groves, which represents a relevant production zone for many typical food products of the Marche region (Conti et al., 2007). Competitor samples were selected by considering the market shares of the leading Italian producers. Notably, for cheese and olive oil, two conventional products were chosen which rank, in terms of sales, in second place in the Agrifood Monitor evaluation (2016) (http://www.agrifoodmonitor.it/en/food-consumption). For the cured ham, since most of the rankings consider PDO or PGI Italian hams, it was selected a conventional product (slightly salty, aged at least 12 months) that is distributed under the retail brand occupying the first position for market share in the Italian large-scale distribution (where the selected PDO products are also available).

All samples have been checked carefully before tasting, to ascertain their origin, storage and packaging.

\subsection{Panel composition}

The sensory panel was composed of 60 volunteers, aged between 18 and 65 years $(60 \%$ female, $40 \%$ male). They came from the Nielsen central geographic area of Italy, which includes Tuscany, Umbria, Marche and Lazio regions. Since the food samples analysed in this study are commonly consumed by the population and can be purchased in large-scale retail channels, the panel included purchase decision-makers who go to the large-scale distribution at least once a week.

Untrained consumers were randomly selected by CIAS Innovation within its community of panellists; they were not chosen for their level of awareness of PDO labels and their meanings, and no training was given to them prior to start the sensory analysis, precisely in order not to influence them. As for the panel size, although an optimal number is not identified, most studies based on sensory analysis employ groups ranging from 50 to 150 untrained subjects (Bertagnolli et al., 2014; Lawless and Heymann, 2010). Accordingly, this research relies on a number of 60 panellists as it is also recommended by the ISO 11136, 2014 standard in order to obtain statistically reliable results in sensory analysis.

\subsection{Data processing}

The results of the acceptance test were examined by applying an analysis of variance (ANOVA) and a Fisher's least significance difference (LSD) procedure for means comparison, by following Lawless and Heymann (2010) and Meilgaard et al.'s (2007) studies. Results with $p<0.05$ were considered to be significant. Notably, the ANOVA test allows to verify the null hypothesis that the mean values related to each sample are equal to each other, against the alternative hypothesis that at least one pair of means has a statistically significant difference. If the ANOVA F-value is significant, the LSD test allows to identify which means are actually different from each other. The significant differences are those larger than the LSD value that is computed according to the following formula:

$$
t \alpha[v]=\sqrt{\frac{2 x M S}{n}}
$$

where:

$$
\begin{aligned}
& \alpha=\text { significant level. } \\
& v=\text { degree of freedom }(\mathrm{df}) . \\
& M S=\text { mean square. } \\
& n=\text { number of observations. }
\end{aligned}
$$


Notably, the LSD procedure protects against type I errors only through the omnibus ANOVA test. With large values of $J$ (with $J$ representing the number of independent groups), it should be avoided as it provides only weak control of type I error. However, when $J=3$ it is effective at controlling both the rate and number of Type I errors (and, because the individual tests are uncorrected, it maximizes statistical power for a given level of $\alpha$ ) (see Baguley, 2012, p. 495; Howell, 2012; Meier, 2006).

Data concerning the consumers' preference, purchase intention and willingness to pay were statistically processed using different tests for statistical significance differences between PDO and non-PDO food samples. Firstly, the Pearson $\chi^{2}$ test was conducted for consumers' preference and purchasing intention. Because some expected cell frequencies were less than 5 and the number of observations was small, as suggested by the literature (Hogg et al., 2005), the Fisher's exact test was further employed in this study. Secondly, the student $t$-test was calculated for comparison of mean values concerning the willingness to pay for PDO and non-PDO foods.

$p$-values less than 0.05 were considered to be statistically significant in all tests.

For completeness of data analysis, statistical tests were computed for all samples' comparisons as shown in Tables 2 and 4. However, only the results specifically concerning the comparison between PDO samples and non-PDO ones have been highlighted and discussed in the next sections of the paper, according to the specific objective of the study (e.g. the statistical comparison between non-PDO samples at a blind and non-blind trial setting becomes less relevant for the research's scope, and thus they were not debated in the paper).

All data were processed by using the XLSTAT 2015.5 statistical software.

\section{Results}

\subsection{Cheese}

Overall, the PDO cheese obtains higher acceptance ratings compared to the competitor (Table 1), concerning both the global acceptance and the sensory attributes' perception (RQ1). Moreover, greater mean values generally emerge from the brand tastings compared to the blind ones, thus revealing the critical influence of brand name on consumers' perception and evaluation of both PDO and non-PDO cheese.

While the mean values are always statistically different at the ANOVA test (Table 1), the LSD procedure reveals some peculiarities (Table 2). Notably, a positive influence of the brand name on global acceptance can be noted as the mean values statistically increase when passing from the blind tasting to the brand one (means PDO cheese: 6.87 vs 7.50; means nonPDO cheese: 5.77 vs 6.43). As concerning the perception of sensory attributes, the appearance of the PDO cheese obtains statistically higher acceptance than the competitor both in the blind (means: 6.87 vs 6.07) and brand tasting (means: 7.30 vs 6.37). For the appearance attribute, however, there is no evidence from the LSD test of a positive effect of the brand name on the degree of acceptance. Similar findings concern the flavour attribute. Regarding the smell, differences between mean values are statistically significant only when comparing the branded samples. In this regard, the PDO cheese receives better acceptance than the nonPDO one (means: 6.00 vs 5.90). Finally, for the texture, the PDO cheese always achieves a statistically greater evaluation in relation to its competitor.

By observing the absolute values in Table 3 , it seems that the PDO label positively affects also the consumers' attitudes of the panellists, in terms of preference, intention to purchase and willingness to pay (RQ2). However, after conducting the tests for significance differences (Table 4), the above influence totally disappears for consumers' preference and purchase intention as the $p$-value is always above 0.05 , while the PDO label improves the consumers' willingness to pay when comparing the PDO cheese with its competitor ( $p$-value $<0.000)$. In this case, a positive effect of the brand name also emerges since the participants' evaluations are greater (and statistically different) in the brand tasting than in the blind one. 
BFJ
123,3

\section{8}

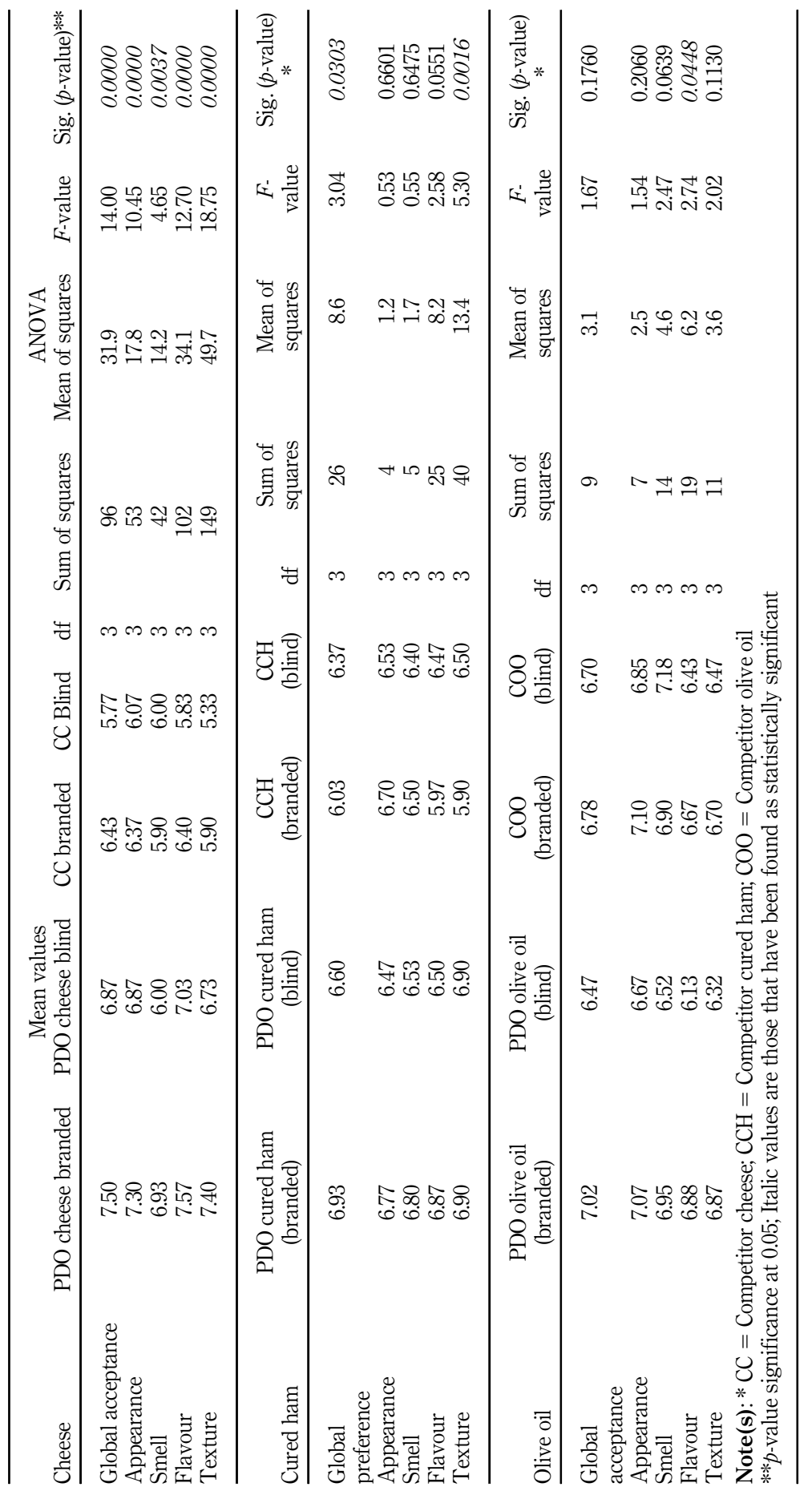

Table 1.

Mean values and ANOVA tests* 


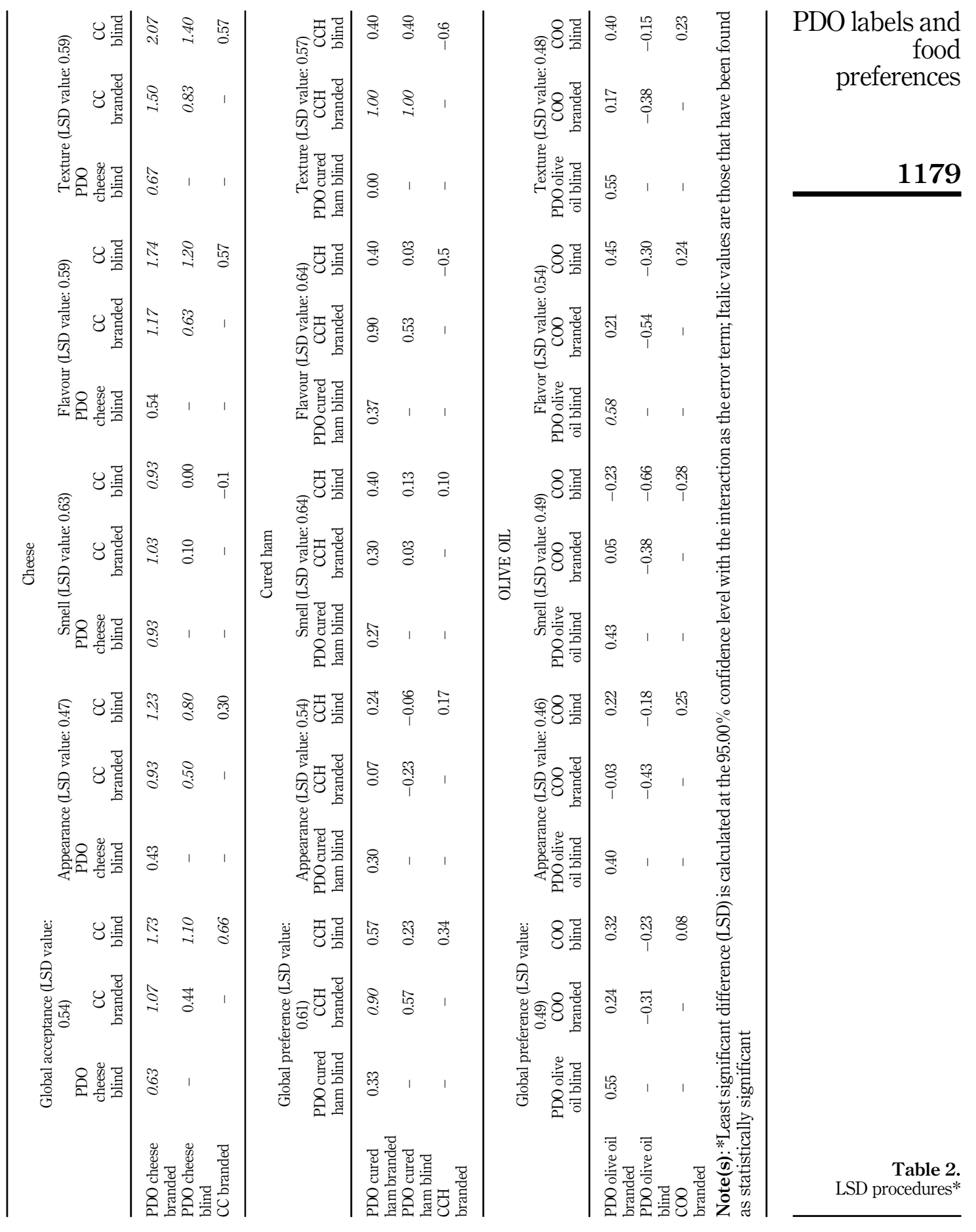


BFJ

123,3

1180

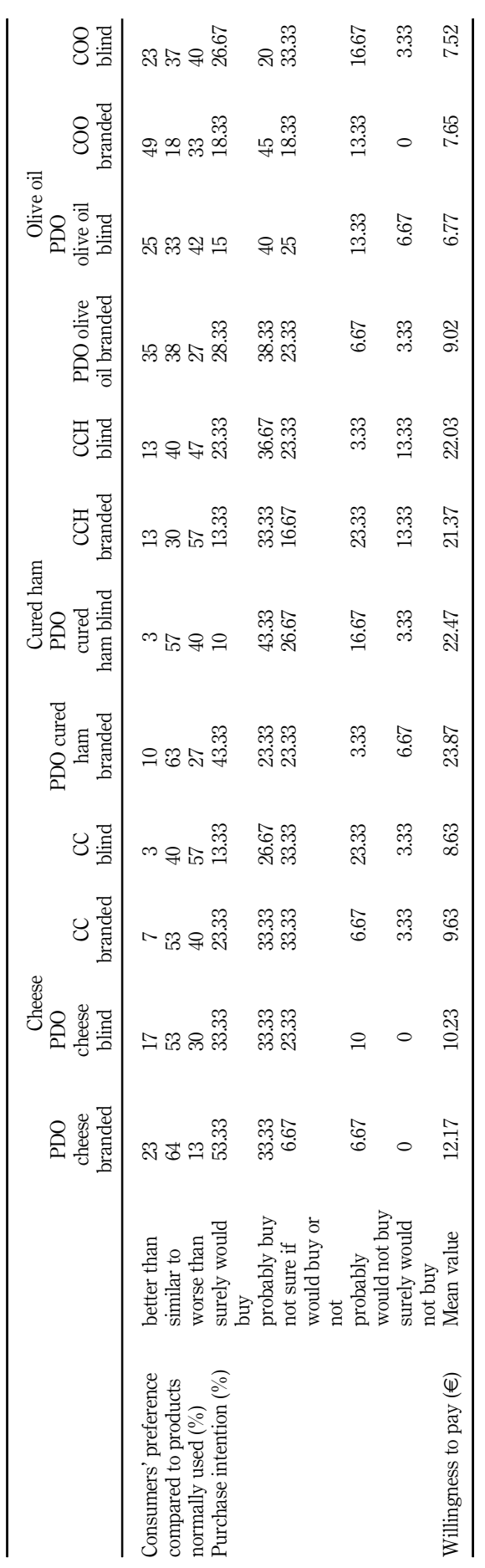

Table 3.

Consumers' preference, purchase intention and willingness to pay
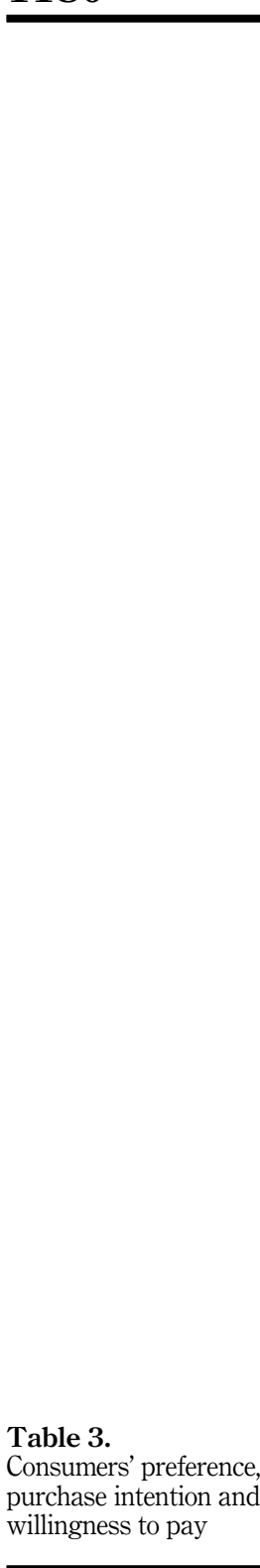


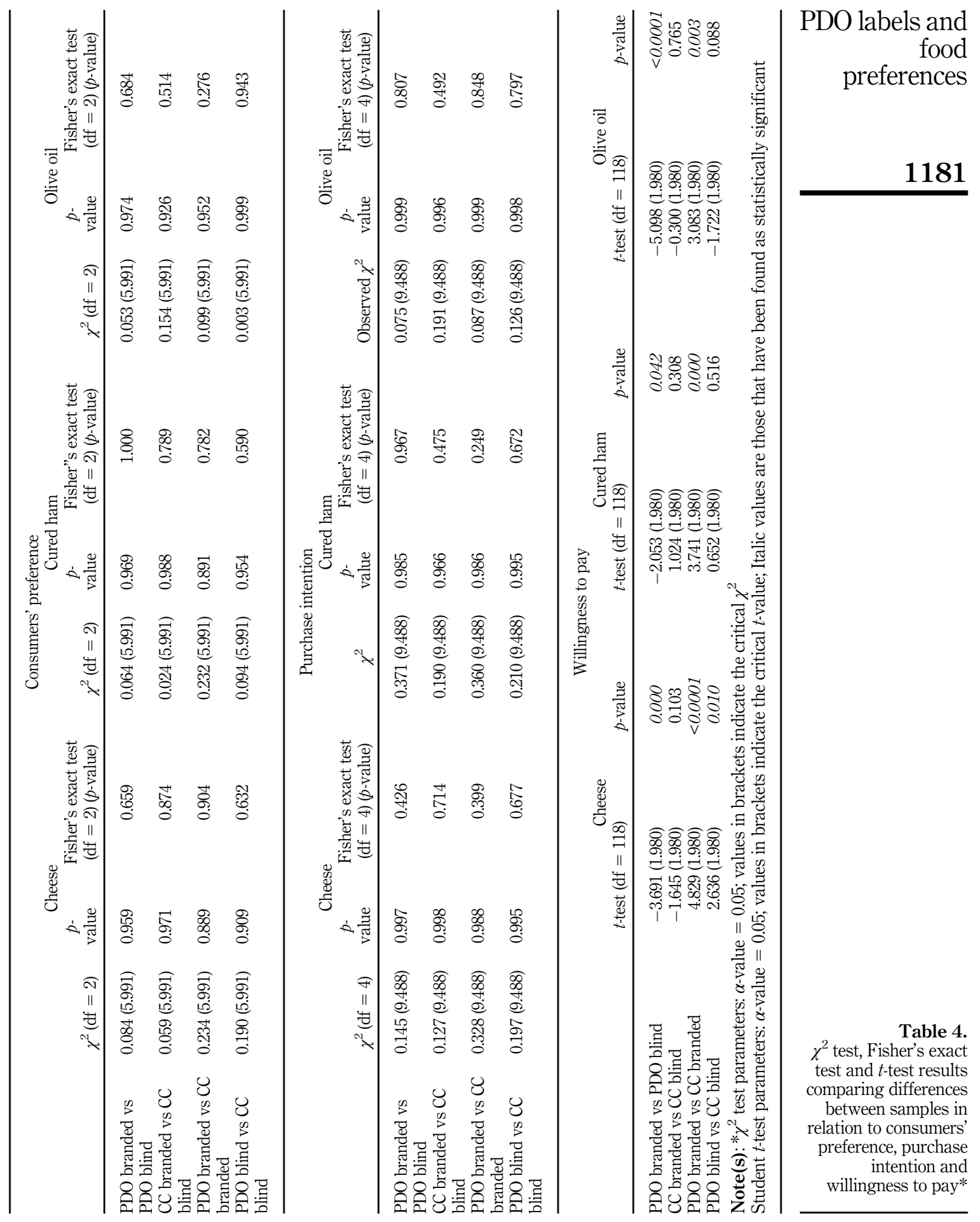


BFJ

123,3

\subsection{Cured ham}

Data from the acceptance test reveal that the perceived difference between the PDO ham and the chosen competitor is not always relevant from a statistical standpoint (RQ1). Notably, the ANOVA test suggests the existence of no statistically significant differences between the PDO sample and the non-PDO one in relation to appearance, smell and flavour attributes, both in the blind and brand tasting (Table 1). This means that the degree of acceptance associated to the above properties does not reveal significant differences in consumers' perception. By contrary, significant differences emerge in terms of global acceptance and texture. The PDO ham performs better than the competitor, both in the blind (means of global acceptance: 6.60 vs 6.37; means of texture: 6.90 vs 6.50) and in the brand tasting (means of global acceptance: 6.93 vs 6.03; means of texture: 6.90 vs 5.90), even though these differences are not always statistically significant in the LSD test (Table 2). In particular, concerning the global acceptance, in the blind tasting the mean values are not statistically different, highlighting a substantial indifference of the consumer with respect to the PDO ham and its competitor, while in the brand tasting the panellists' acceptance for the PDO ham statistically increases. Similar findings emerge in relation to the texture. The branded tasting produces a positive and statistically significant effect on the consumers' acceptance, which is higher for the PDO product compared to its competitor (means: 6.90 vs 5.90).

Regarding the consumers' attitudes (RQ2), results are very similar to those concerning the cheese sample. The influence of the PDO label on consumers' preference and purchasing intention is not significant at statistical examination $(p$-value $>0.05)$, while it becomes relevant for willingness to pay ( $p$-value $<0.05$ ), which is not independent from PDO presence, especially when comparing the PDO ham with the non-PDO sample. In these cases, the willingness to pay increases when passing from blind to brand tasting, thus confirming the important role of brand name besides that of PDO labels.

\subsection{Olive oil}

The results of the acceptance test for olive oil reveal a lower degree of perceived differences between the PDO product and the chosen competitor (RQ1). The distance between the mean values, in absolute terms, is slightly evident, and the ANOVA test does not reveal statistically significant differences among them, except for the flavour attribute (Table 1). In this respect, during the blind tasting, the degree of acceptance of the PDO oil is lower than that of the competitor (means: 6.13 vs 6.43), while an opposite situation occurs in the brand tasting (means: 6.88 vs 6.67). The Fisher's procedure shows that the difference between mean values found in the blind and brand tests are significant only for the PDO sample, therefore no significant effect of brand name on the consumers' acceptance exists for the non-PDO sample with specific reference to the flavour attribute (Table 2).

Regarding the consumers' attitudes (RQ2), again the $\chi^{2}$ test and the Fisher's exact test do not reveal the existence of statistically significant differences between PDO and non-PDO olive oil when considering the consumers' preference and purchasing intention ( $p$-value $>0.05$ ). On the contrary, the $t$-test indicates that the willingness to pay is positively affected by the presence of the PDO label, especially when the brand name is visible to the subject ( $p$-value lower than 0.05) (Table 3).

Finally, in the case of olive oil, there is a very little effect produced by the PDO label and the brand name on both global acceptance and sensory attributes' perception, as well as on consumers' attitudes expressed in terms of preference and purchasing intention.

\section{Discussion and implications}

By comparing the results obtained in the blind and brand tasting of this study, it is possible to summarize the influence that PDO labels exert on both consumers' acceptance and perception 
of sensory attributes and on their attitudes towards products analysed. Overall, Table 1 shows that mean values above 6.0 were obtained for the general acceptance of PDO samples as well as for their attributes' perception, thus suggesting a good acceptance by consumers of PDO products (Muñoz et al., 1992). Moreover, the absolute values are generally higher for PDO products compared to non-PDO ones, which seems to suggest the positive influence of PDO label on the global acceptance and attributes' perception of consumers. Nevertheless, the ANOVA test and the LSD procedure reveal that the above differences are not always significant from a statistical perspective. Notably, the sensory attributes' perception is clearly dependent on the presence of the PDO label only in the case of cheese, while for the olive oil the effect of the PDO label is statistically irrelevant also concerning the global acceptance. These findings lead to the conclusion that the consumers' acceptance of product in the food context cannot be generalized as it depends on the product type and characteristics (RQ1). Similarly, our findings reveal that the PDO label does not affect the consumers' preference, while it produces a general increasing in the willingness to pay, as previously demonstrated by Van Ittersum et al. (2007) and Cacchiarelli et al. (2016), which in turn can be considered as an important indicator of purchase intention (RQ2).

Theoretical and practical implications can be drawn by focussing on three main aspects, concerning: (1) the critical role, albeit differentiated by product categories, of the PDO label, (2) the importance of brand name as an enhancer of consumer acceptance and attitudes towards PDO products and (3) the recognition of sensory attributes that are most appreciated by consumers when tasting and evaluating different product categories.

\subsection{Theoretical implications}

From a theoretical perspective, the critical role of PDO label as an enhancer of consumers' acceptance and preference, especially observed in the case of cheese, is consistent with prior research that highlights a growing attention of subjects towards PDO foods (e.g. Fandos and Flavian, 2006; Espejel et al., 2008). However, evidences from the acceptance test do not allow to generalise theaboveresults since statistical differences in consumers' acceptance of PDOproducts compared to non-PDO ones clearly emerge only for cheese. The mean values related to cured ham and olive oil are statistically different only with respect to some attributes, and mainly in the brand tasting phase (i.e. when consumers are informed about the brand name and the product origins). This may be due to a consumer's ability to detect the differences between products. Notably, in the case of olive oil, it could be very difficult for a common and untrained subject to recognize the differences between samples and express them in terms of acceptance. Overall, this suggests that, under such conditions, the PDO label improves its positive influence on consumers' acceptance when they are informed about its brand name. In this respect, our findings add empirical evidence to prior literature, being in line with Espejel et al. (2008) suggesting that the knowledge of the brand name is an important asset for the umbrella brand which is thePDO, and effective brand strategies are helpful for improving the overall PDO label effectiveness.

Further considerations concerning the brand name can be drawn, by evaluating its role in affecting the consumers' preference not only for PDO products but also for non-PDO ones. Taken as a whole, this result is consistent with a large number of past studies investigating the influence of brand name on consumer response (e.g. Laforet, 2011; Murray and Delahunty, 2000; Rao and Monroe, 1989). However, by analysing the acceptance test data, statistical differences $(p<0.05)$ were not always observed in consumers' acceptance of the products where brand was added. Therefore, our sensory analysis suggests that one must use caution when generalizing results concerning the positive influence of brand name on consumer response and perception. This provides further evidence to prior results of Di Monaco et al. (2004, p. 436), demonstrating that the "knowledge of brand name did not affect the perception of sensory attributes", as "the expectations generated by the brand name are essentially of the hedonic-based type". 
BFJ

123,3

1184

Finally, as concerning the importance of sensory attributes, results show that flavour and texture are the most important attributes affecting the sensory perception of cheese and cured ham, especially in the brand tasting phase. Appearance and smell, on the other hand, increase their importance for the olive oil evaluation, as well as in tasting the food samples under blind conditions. Therefore, results reveal that the lower the consumer knows about the product brand and its origins, the higher is the importance of those attributes that are easily perceptible by human senses, like appearance and smell. Moreover, in the case of olive oil, these attributes become particularly relevant because it is very difficult to recognize differences among products in terms of flavour or texture, especially for untrained consumers. This goes beyond prior research that informs about the highest importance of brand names and quality labels when intrinsic properties, including sensory attributes, are difficult to evaluate for the consumer (Fotopoulos and Krystallis, 2001), by considering the opposite situation in which consumers have no information about the brand name and the intrinsic attributes of food are difficult to evaluate. In this case, results suggest that consumers tend to rely on sensory attributes that are easier to perceive through their senses.

Overall, this study shows that PDO labels seem to have more a connection with the consumers' acceptance and perception of sensory attributes of products than to their behavioural traits. If we consider the willingness to pay as an indicator of purchase intention, our results are consistent with prior research (Van Ittersum et al., 2007; Cacchiarelli et al., 2016) highlighting that consumers of regional products are sensitive to PDO labels as these are synonymous of quality warranty and allow to give local economic support. Nevertheless, when specifically measuring the intention to purchase and the consumers' preference, no differences emerged from our study between PDO and non-PDO samples, thus leading to the conclusion that PDO labels are not relevant in affecting the consumers' behaviour and decision process. This can be considered in line with the works of Fotopoulos and Krystallis (2001) and Marcoz et al. (2016) who demonstrated that PDO labels do not always have relevance in influencing consumer attitudes. However, our findings go beyond existing research, by revealing that consumers could be positively influenced by PDO labels at a psychological level even if they seem to be unaffected from a behavioural standpoint. This was passible to understand only thanks to the sensory methodological approach that was used in this study, which contributes to provide further implications for managers and practitioners.

\subsection{Managerial implications}

As far as practical implications are considered, a first suggestion concerns the PDO label management. Although a general judgement of acceptance emerged for the PDO products, the statistical tests revealed different situations for the samples analysed. This implies the need for companies to continue investing to improve the level of consumer knowledge of certifications labels, especially for certain product categories. It can be done through dedicated courses, workshops organized in collaboration with universities or other educational institutions and other initiatives targeted at both adults and younger generations aimed at improving their sensitivity and encouraging a favourable attitude towards certified products. For olive oil, in particular, it could be possible to organize initiatives within the same company or in their oil mills. These activities, following the model of educational farms, could offer moments of meeting, training and debate on relevant issues, such as product certification. Overall, the above initiatives could help consumers to improve their knowledge about certification labels and, consequently, their acceptance and behavioural response.

Secondly, these initiatives aimed at strengthening the consumer awareness towards certifications should be accompanied by appropriate branding strategies. Our findings, indeed, suggest the importance of investing in branding strategies to increase the acceptance and preference of both PDO and non-PDO foods. The competitive ability of the typical product cannot be based exclusively on the superiority of its intrinsic qualities, even if these 
are certified by GI schemes. This superiority must be communicated, and the product strategy must be accompanied by an adequate branding strategy. It is important to insist on the unique qualities of the PDO products, making the presence of the PDO label clearly visible, also through the communication of this label (perhaps accompanied by a very brief explanation) or of other certifications attesting the origin and quality of the product.

Finally, the results suggest the importance of working on some product attributes most affecting a consumer's perception. The findings show that flavour and texture are the most important attributes affecting the sensory properties of cheese and cured ham, especially in the brand tasting phase. Appearance and smell, on the other hand, increase in importance for the evaluation of olive oil, as well as in tasting the products under blind conditions. This could inform companies about the sensory proprieties on which to focus their attention for increasing the global acceptance and success of the typical and PDO products.

\section{Conclusions, limitations and future research}

Notwithstanding the differences between product categories, a critical role of the PDO label generally emerges in this study. Through a cross-sectional comparison between categories, the perceived differences between PDO and non-PDO products are very evident in the case of cheese, while they tend to be less evident in cured ham and they almost disappear in the case of olive oil. We conclude that the presence of PDO labels on consumers' acceptance and perception of sensory attributes' (RQ1), as well as on consumers' preference and purchase intention (RQ2), can be considered as relevant, but it should not be generalized. Notably, this study, owing to the sensory methodology used for its development, compared to what has been done in the past research, contributes to enriching the literature on the perception of the importance of the PDO label by consumers, which has been revealed as particularly relevant in the evaluation of the sensory attributes of products.

Although these results provide useful insights into the body of literature on the PDOconsumer relationship and suggest practical implications for companies, there are some limitations that are worth highlighting.

The acceptability and preference gaps found in the comparison between PDO and nonPDO products suggest the need of investigating their possible motives, in order to formulate indications of higher values for both marketers and companies that are engaged in differentiation strategies anchored to typical products. The data collected in this study are not enough to understand motivations underlying the above differences. This is the first limitation of the research that could inspire future studies, based on different methods, such as in-depth interviews, aimed at exploring the hidden motives underlining the consumers' preferences and behaviours.

Moreover, a lab study usually does not allow the product consumption during a "normal" situation. Thus, future studies could evaluate the possibility of using a mobile laboratory, to create sensory performances that are closer to the real consumption situations and/or to develop an analysis directly at a consumer's home, to evaluate the products in their daily context. The latter analysis, in particular, would permit to obtain also information about products' preparation, shelf life, packaging, versatility of use, etc.

Another limitation is related to the panel composition. Although the number of adopted volunteers is compatible with the requirements of European legislation, it is limitedand localized in a specific geographic area of Italy. Future studies would extend the analysis, with other sensory tests, as well as other techniques, to a larger and representative sample of the population.

Finally, this study focussed the attention on three PDO products that are produced in the Province of Pesaro and Urbino. Future works could consider a greater number of certified products from other geographical regions of Italy, or from other countries, to improve the overall comprehension of similarities and differences. 
BFJ

123,3

1186

\section{References}

Agrifood Monitor evaluation (2016), "Food consumption”, 1, available at: http://www.agrifoodmonitor. it/en/food-consumption (accessed 12 March 2020).

Alfian, G., Rhee, J., Ahn, H., Lee, J., Farooq, U., Ijaz, M.F. and Syaekhoni, M.A. (2017), "Integration of RFID, wireless sensor networks, and data mining in an e-pedigree food traceability system", Journal of Food Engineering, Vol. 212, pp. 65-75, doi: 10.1016/j.jfoodeng.2017.05.008.

Asioli, D., Varela, P., Hersleth, M., Almli, V.L., Olsen, N.V. and Naes, T. (2017), "A discussion of recent methodologies for combining sensory and extrinsic product properties in consumer studies", Food Quality and Preference, Vol. 56 No. B, pp. 266-273, doi: 10.1016/j.foodqual.2016.03.015.

Aumatell, M.R. (2011), "Sensory analysis in quality control: the gin as an example", in Akyar, I. (Ed.), Wide Spectra of Quality Control, InTech, Rijeka, pp. 361-372.

Baguley, T. (2012), Serious Stats: A Guide to Advanced Statistics for the Behavioral Sciences, Macmillan International Higher Education, New York, NY.

Bertagnolli, S.M.M., Silveira, M.L.R., Fogaça, A.D.O., Umann, L. and Penna, N.G. (2014), "Bioactive compounds and acceptance of cookies made with Guava peel flour", Food Science and Technology, Vol. 34 No. 2, pp. 303-308, doi: 10.1590/fst.2014.0046.

Bonetti, E., Mattiacci, A. and Simoni, M. (2019), "Communication patterns to address the consumption of PDO products”, British Food Journal, Vol. 122 No. 2, pp. 390-403, doi: 10.1108/BFJ-03-2019-0204.

Bryła, P. (2017), "The perception of EU quality signs for origin and organic food products among Polish consumers", Quality Assurance and Safety of Crops and Foods, Vol. 9 No. 3, pp. 345-355.

Bryła, P. (2019), "Regional ethnocentrism on the food market as a pattern of sustainable consumption", Sustainability, Vol. 11 No. 22, p. 6408.

Cacchiarelli,L.,Carbone, A.,Laureti, T.and Sorrentino, A.(2016), “The value of different quality clues in the Italian olive oil market", Italian Review of Agricultural Economics, Vol. 71 No. 1, pp. 372-379.

Cilla, I., Martínez, L., Guerrero, L., Guàrdia, M.D., Arnau, J., Altarriba, J. and Roncalés, P. (2006), "Consumer beliefs and attitudes towards dry-cured ham and protected designation of origin Teruel ham in two Spanish regions differing in product knowledge", Food Science and Technology International, Vol. 12 No. 3, pp. 229-240.

Conti, M.E., Stripeikis, J., Campanella, L., Cucina, D. and Tudino, M.B. (2007), "Characterization of Italian honeys (Marche region) on the basis of their mineral content and some typical quality parameters", Chemistry Central Journal, Vol. 1 No. 14, doi: 10.1186/1752-153X-1-14.

De Pelsmaeker, S., Dewettinck, K. and Gellynck, X. (2013), "The possibility of using tasting as a presentation method for sensory stimuli in conjoint analysis", Trends in Food Science and Technology, Vol. 29 No. 2, pp. 108-115, doi: 10.1016/j.tifs.2012.10.001.

Di Monaco, R., Cavella, S., Di Marzo, S. and Masi, P. (2004), "The effect of expectations generated by brand name on the acceptability of dried semolina pasta", Food Quality and Preference, Vol. 15 No. 5, pp. 429-437, doi: 10.1016/j.foodqual.2003.07.003.

Dias, C. and Mendes, L. (2018), "Protected designation of origin (PDO), protected geographical indication (PGI) and traditional speciality guaranteed (TSG): a bibiliometric analysis", Food Research International, Vol. 103, pp. 492-508, doi: 10.1016/j.foodres.2017.09.059.

Dijksterhuis, G.B. and Byrne, D.V. (2005), "Does themind reflect the mouth? Sensory profiling and the future", Critical Reviews in Food Science and Nutrition, Vol. 45 Nos 7-8, pp. 527-534, doi: 10.1080/ 10408690590907660.

Dora, M., Kumar, M., Van Goubergen, D., Molnar, A. and Gellynck, X. (2013), “Operational performance and critical success factors of lean manufacturing in European food processing SMEs", Trends in Food Science and Technology, Vol. 31 No. 2, pp. 156-164, doi: 10.1016/j.tifs.2013.03.002.

Erraach, Y., Sayadi, S., Gomez, A.C. and Parra-Lopez, C. (2014), "Consumer-stated preferences towards protected designation of origin (PDO) labels in a traditional olive-oil-producing country: the case of Spain”, New Medit, Vol. 13 No. 4, pp. 11-19. 
Espejel, J., Fandos, C. and Flavián, C. (2008), “Consumer satisfaction: a key factor of consumer loyalty and buying intention of a PDO food product", British Food Journal, Vol. 110 No. 9, pp. 865-881, doi: $10.1108 / 00070700810900585$.

Fandos, C. and Flavián, C. (2006), "Intrinsic and extrinsic quality attributes, loyalty and buying intention: an analysis for a PDO product", British Food Journal, Vol. 108 No. 8, pp. 646-662, doi: 10.1108/00070700610682337.

Fotopoulos, C. and Krystallis, A. (2001), "Are quality labels a real marketing advantage? A conjoint application on Greek PDO protected olive oil", Journal of International Food and Agribusiness Marketing, Vol. 12 No. 1, pp. 1-22, doi: 10.1300/J047v12n01_01.

Frandsen, L.W., Dijksterhuis, G., Brockhoff, P., Nielsen, J.H. and Martens, M. (2007), "Feelings as a basis for discrimination: comparison of a modified authenticity test with the same-different test for slightly different types of milk", Food Quality and Preference, Vol. 18 No. 1, pp. 97-105, doi: 10.1016/j.foodqual.2005.08.006.

Garavaglia, C. and Mariani, P. (2015), "How much do consumers value PDO certifications? Estimates of WTP for PDO Dry-Cured Ham in Italy", Paper prepared for the 145th EAAE Seminar 'Intellectual Property Rights for Geographical Indications: what is at Stake in the TTIP?', April 14-15, Parma, Italy, pp. 1-33.

Grunert, K.G. and Aachmann, K. (2016), "Consumer reactions to the use of EU quality labels on food products: a review of the literature", Food Control, Vol. 59, pp. 178-187, doi: 10.1016/j.foodcont. 2015.05.021.

Hajdukiewicz, A. (2014), "European Union agri-food quality schemes for the protection and promotion of geographical indications and traditional specialities: an economic perspective", Folia Horticulturae, Vol. 26 No. 1, pp. 3-17, doi: 10.2478/fhort-2014-0001.

Hogg, R.V., McKean, J. and Craig, A.T. (2005), Introduction to Mathematical Statistics, Pearson Education, Upper Saddle River, NJ.

Howell, D.C. (2012), Statistical Methods for Psychology, Cengage Learning, Boston, Massachusetts.

ISMEA-Fondazione Qualivita (2018), Rapporto 2018 Sulle Produzioni Agroalimentari e Vitivinicole Italiane, Edizioni Qualivita, Roma (IT).

ISO 11136 (2014), Sensory Analysis Methodology. General Guidance for Conducting Hedonic Tests with Consumers in a Controlled Area, ISO, Geneva.

ISO 22000 (2005), Food Safety Management Systems - Requirements for Any Organization in the Food Chain, ISO, Geneva.

Kim, M.A., Sim, H.M. and Lee, H.S. (2015), “Affective discrimination methodology: determination and use of a consumer-relevant sensory difference for food quality maintenance", Food Research International, Vol. 70, pp. 47-54, doi: 10.1016/j.foodres.2015.01.027.

Kim, M., Tang, C.H. and Roehl, W.S. (2018), "The effect of hotel's dual-branding on willingness-to-pay and booking intention: a luxury/upper-upscale combination", Journal of Revenue and Pricing Management, Vol. 17 No. 4, pp. 256-275.

Kos Skubic, M., Erjavec, K., Ule, A. and Klopčič, M. (2018), "Consumers' hedonic liking of different labeled and conventional food products in Slovenia”, Journal of Sensory Studies, Vol. 33 No. 5, e12444, doi: 10.1111/joss.12444.

Kos Skubic, M., Erjavec, K. and Klopčič, M. (2019), "Consumer awareness of PDO-labelled food in Slovenia”, Italian Journal of Animal Science, Vol. 18 No. 1, pp. 366-371, doi: 10.1080/1828051X. 2018.1530959.

Lähteenmäki, L. (2013), "Claiming health in food products”, Food Quality and Preference, Vol. 27 No. 2, pp. 196-201, doi: 10.1016/j.foodqual.2012.03.006.

'Laforet, S. (2011), "Brand names on packaging and their impact on purchase preference", Journal of Consumer Behaviour, Vol. 10 No. 1, pp. 18-30, doi: 10.1002/cb.343.

Lawless, H.T. and Heymann, H. (2010), Sensory Evaluation of Food: Principles and Practices, Springer Science and Business Media, Berlin. 
BFJ 123,3

Lyon, D.H., Francombe, M.A. and Hasdell, T.A. (2012), Guidelines for Sensory Analysis in Food Product Development and Quality Control, Springer Science and Business Media, Berlin.

Mallia, S., Fernández-García, E. and Olivier Bosset, J. (2005), "Comparison of purge and trap and solid phase microextraction techniques for studying the volatile aroma compounds of three European PDO hard cheeses", International Dairy Journal, Vol. 15 Nos 6-9, pp. 741-758, doi: 10. 1016/j.idairyj.2004.11.007.

Marcoz, E.M., Melewar, T.C. and Dennis, C. (2016), "The value of region of origin, producer and protected designation of origin label for visitors and locals: the case of fontina cheese in Italy", International Journal of Tourism Research, Vol. 18 No. 3, pp. 236-250, doi: 10.1002/jtr.2000.

Meier, U. (2006), "A note on the power of fisher's least significant difference procedure", Pharmaceutical Statistics: The Journal of Applied Statistics in the Pharmaceutical Industry, Vol. 5 No. 4, pp. 253-263.

Meilgaard, M., Civile, G.V. and Carr, B.T. (2007), Sensory Evaluation Techniques, 4th ed., CRC Press, Florida.

Menapace, L., Colson, G., Grebitus, C. and Facendola, M. (2011), "Consumers' preferences for geographical origin labels: evidence from the Canadian olive oil market", European Review of Agricultural Economics, Vol. 38 No. 2, pp. 193-212, doi: 10.1093/erae/jbq051.

Mora, M., Elzo-Aizarna, J., Rozas-Fuertes, S., Velilla-Echeita, L. and Vázquez-Araújo, L. (2020), "Implicit reaction vs explicit emotional response: protected designation of origin in apple cider", Food Quality and Preference, Vol. 79, p. 103773, doi: 10.1016/j.foodqual.2019.103773.

Muñoz, A.M., Civille, V.G. and Carr, B.T. (1992), Sensory Evaluation in Quality Control, Van Nostrand Reinhold, New York, NY.

Murray, J.M. and Delahunty, C.M. (2000), "Mapping consumer preference for the sensory and packaging attributes of Cheddar cheese", Food Quality and Preference, Vol. 11 No. 5, pp. 419-435, doi: 10.1016/S0950-3293(00)00017-3.

Nosi, C. and Zanni, L. (2004), "Moving from 'typical products' to 'food-related services': the Slow Food case as a new business paradigm", British Food Journal, Vol. 106 Nos 10/11, pp. 779-792, doi: 10. 1108/00070700410561388.

Peryam, D.R. and Girardot, N.F. (1952), “Advanced taste test method”, Food Engineering, Vol. 24 No. 194, pp. 58-61.

Rafeeque, K.T. and Sekharan, N. (2018), "Multiple food safety management systems in food industry: a case study", International Journal of Food Science and Nutrition, Vol. 3 No. 1, pp. 37-44, available at: https://ssrn.com/abstract $=3104402$.

Rao, A.R. and Monroe, K.B. (1989), "The effect of price, brand name, and store name on buyers' perceptions of product quality: an integrative review", Journal of Marketing Research, Vol. 26 No. 3, pp. 351-357, doi: 10.1177/2F002224378902600309.

Resano, H., Sanjuán, A.I. and Albisu, L.M. (2007), “Consumers' acceptability of cured ham in Spain and the influence of information", Food Quality and Preference, Vol. 18 No. 8, pp. 1064-1076.

Rodrigues, L., Machado, M. and Pinheiro, C. (2018), “Cheese: food perception and food choice”, Recent Patents on Food, Nutrition and Agriculture, Vol. 9 No. 2, pp. 104-110, doi: 10.2174/ 2212798410666180705092257.

Savelli, E., Bravi, L., Murmura, F. and Pencarelli, T. (2019a), "Understanding the consumption of traditional-local foods through the experience perspective: the case of the truffle", British Food Journal, Vol. 121 No. 6, pp. 1261-1280, doi: 10.1108/BFJ-05-2018-0290.

Savelli, E., Murmura, F., Liberatore, L., Casolani, N. and Bravi, L. (2019b), "Consumer attitude and behaviour towards food quality among the young ones: empirical evidences from a survey", Total Quality Management and Business Excellence, Vol. 30 Nos 1-2, pp. 169-183, doi: 10.1080/ 14783363.2017.1300055.

Silva, J.D.O. and Ferreira, L.D.A. (2017), "Sensory analysis: the attributes of packaging and pharmaceutical forms of nail strengtheners commercialized in Brazil", International Journal of 
Pharmacy and Pharmaceutical Sciences, Vol. 9 No. 6, pp. 176-179, doi: 10.22159/ijpps. PDO labels and 2017v9i6.15491.

Spears, N. and Singh, S.N. (2004), "Measuring attitude toward the brand and purchase intentions", Journal of Current Issues and Research in Advertising, Vol. 26 No. 2, pp. 53-66, doi: 10.1080/ 10641734.2004.10505164.

Tendero, A. and Bernabéu, R. (2005), "Preference structure for cheese consumers. A Spanish case study”, British Food Journal, Vol. 107 No. 2, pp. 60-73, doi: 10.1108/00070700510579144.

Trabelsi-Trigui, I. and Giraud, G. (2012), "Exploring region of origin labelling food products as a new experiential brand strategy”, Journal of Marketing Research and Case Studies, Vol. 2012, pp. 1-14, doi: 10.5171/2012.600938.

Tung, S.J., Shih, C.C., Wei, S. and Chen, Y.H. (2012), "Attitudinal inconsistency toward organic food in relation to purchasing intention and behaviour", British Food Journal, Vol. 114 No. 7, pp. 997-1015.

UNI EN ISO 8589 (2010), Analisi Sensoriale - Guida Generale per la Progettazione di Locali di Prova, UNI, Milano.

Van Ittersum, K., Meulemberg, M.T.G., Van Trijp, H.C.M. and Candel, M.J.J. (2007), “Consumers' appreciation of regional certification labels: a pan-European study", Journal of Agricultural Economics, Vol. 58 No. 1, pp. 1-23, doi: 10.1111/j.1477-9552.2007.00080.x.

Vermeir, I. and Verbeke, W. (2006), "Sustainable food consumption: exploring the consumer attitudebehavioural intention'gap", Journal of Agricultural and Environmental Ethics, Vol. 19, pp. 169-194, doi: 10.1007/s10806-005-5485-3.

$\mathrm{Xu}, \mathrm{X}$., Zeng, S. and He, Y. (2017), "The influence of e-services on customer online purchasing behavior toward remanufactured products", International Journal of Production Economics, Vol. 187, pp. 113-125.

\section{Corresponding author}

Federica Murmura can be contacted at: federica.murmura@uniurb.it

For instructions on how to order reprints of this article, please visit our website:

www.emeraldgrouppublishing.com/licensing/reprints.htm

Or contact us for further details: permissions@emeraldinsight.com 